\title{
Trazos de Cristo en América Latina. Ensayos teológicos
}

Jorge Costadoat, S.J.

Jorge Costadoat, S.J., reúne, en un solo volumen, once artículos publicados en diversas revistas teológicas, mayoritariamente en los últimos años de la década de 2000, aunque también algunos en los años 90. Por tratarse de una recopilación, el autor advierte que cada texto puede ser abordado de manera independiente y que el libro puede ser leído siguiendo cualquier orden. Él mismo, sin embargo, afirma que el conjunto sí tiene algunas columnas que le dan vertebración unitaria, por lo que agrupa los textos en tres secciones más gruesas.

Los tres artículos de la primera parte se agrupan bajo el título «Fe en Dios en América Latina». El primero de ellos, «La pregunta por Dios en la Teología de la Liberación», tiende un arco que va desde los trabajos de Juan Luis Segundo hasta los de Gustavo Gutiérrez, entre otros, en busca de una formulación adecuada de la pregunta sobre Dios en el contexto de un continente víctima de la injusticia pero al mismo tiempo masivamente creyente. Descartada la pertinencia de la pregunta acerca de la existencia de Dios, propia de la teología europea en conflicto con el racionalismo, la disputa entre fe y ateísmo cede su lugar a otra polaridad diferente, que suponiendo la existencia de Dios, se interroga más bien por el rostro del Dios verdadero. La polaridad en este caso se produce entre fe e idolatría, y en Gustavo Gutiérrez alcanza su ultimidad bajo la forma de un interrogante respecto de cómo es posible hablar de un Dios bueno, amoroso y justo en un continente donde los motivos para desconfiar de un Dios semejante son tan patentes. No se trata solo de desenmascarar a los dioses 
falsos -los ídolos- recuperando con ello un tópico presente en la historia de la fe de Israel como un motivo actual y pleno de sentido, sino de hacer a continuación una afirmación plausible sobre la positividad del Dios verdadero a partir de la experiencia de quienes, teniendo todos los motivos para desconfiar de Él, sin embargo, lo profesan y le renuevan su confianza precisamente porque en medio de las injusticias lacerantes de que son víctimas, no tienen en quién confiar más que en Él. Algunas de las cuestiones tratadas en este artículo resurgen en «Ideas centrales de la Cristología de Jon Sobrino» $\mathrm{y}$ «Cristo Liberador, mediador absoluto del reino de Dios», en la segunda parte del libro.

El segundo artículo de la primera parte, «La recepción de Aparecida», propone algunas claves hermenéuticas para la recepción del documento final de la V Conferencia del Episcopado Latinoamericano celebrada en Aparecida en 2007, y guarda relación con los artículos de la segunda parte, «La necesidad de un encuentro con Cristo» y «El seguimiento comunitario del Señon», en la medida en que se comentan en ellos las diversas aristas del llamado de Aparecida a los católicos para misionar. En «La recepción de Aparecida», el padre Costadoat sostiene que la V Conferencia del CELAM ha venido a reafirmar la teología de los signos de los tiempos como parte del acervo propio de la teología latinoamericana postconciliar, y bajo esa premisa, Aparecida reafirma además la opción por los pobres, ya no solo como lugar hermenéutico, sino como lugar teológico. Aunque es cierto que al menos desde la conferencia de Puebla de 1978, la identificación de los pobres se ha diversificado en numerosos rostros de Cristo, el analogado principal sigue siendo los pobres que nos son mostrados por la ciencia social, aquellos cuya condición menoscabada en la sociedad no es fruto de accidentes fortuitos, sino de la operación sistemática y cotidiana de instituciones sociales injustas, aquella violencia institucionalizada de que nos hablaba la II Conferencia del CELAM en Medellín en 1968. No obstante, en tiempos de globalización en que la primacía de la rentabilidad del capital y la expansión tecnológica han convertido al trabajo humano en un factor productivo aún más subordinado que antaño, en un costo del que se puede prescindir racionalmente en tanto sea posible y económicamente effciente, la pobreza no solo se traduce en situaciones de desigualdad y de explotación del trabajo, sino más grave aún, de exclusión social 
de todos aquellos cuyo trabajo ni siquiera hace falta explotar porque no se lo requiere. Es entonces que Aparecida advierte en contra de esta forma más radical de pobreza, que hace del pobre alguien sobrante o desechable para la sociedad. Llama la atención en este artículo la presentación que el padre Costadoat hace del documento de Aparecida como un texto dinámico y vivo, que puede acertar y errar, y que nos acompañará de camino a la VI Conferencia, un instrumento de trabajo que al mismo tiempo que sirve de inspiración, deja abiertas algunas preguntas insuficientemente tratadas en él. Por ejemplo, lo referente a hacerse cargo de los actuales déficits del discurso social de la Iglesia; los reclamos de las culturas locales frente al despliegue homogeneizador de la globalización tecnológica y económica; y el papel de la mujer, todavía injustamente relegada a un lugar subordinado tanto en la Iglesia como en la sociedad. Asimismo, puesto que el llamado a misionar se formula en términos de seguimiento de Cristo, la necesidad de enfatizar que ese seguimiento de la persona de Cristo no puede reducirse a una fuga del mundo, o a una privatización intimista de la relación personal con él, sino que debe enmarcase en una reafirmación de la libertad personal de quien cree que la medida de su amor a Dios y a sí mismo es el amor que profesa por el prójimo. Libertad individual, espiritualidad, que se traduce, por fin, en la búsqueda de la vida comunitaria y en vaciamiento o don de sí a favor de otros, a imitación de lo que enseña la imagen de Dios como reunión y comunicación amorosa de tres personas.

El tercer artículo de la primera parte, «Diálogo de la Teología con la cultura», guarda conexión con el tercer artículo de la segunda parte, «Cristo liberador, mediador absoluto del Reino de Dios». En ellos se abordan dos cuestiones principales. Una, el que la teología ha de estar al servicio de la pastoral. En efecto, el reino de Dios anunciado por Jesús no es algo que apela solo ni principalmente al asentimiento cognitivo de un credo, sino que es la repetición en la historia de la experiencia de una relación personal de los hijos con el Dios que se hace llamar Padre y que al ser amor, implica con ello que creer en Él es creer que nos ama y que está dispuesto a cumplir sus promesas de vida eterna como rehabilitación para quienes han sido víctimas de la injusticia. Contra ciertos rasgos heredados del helenismo -que hace de la fe una cuestión de asentimiento intelectual de un Dios que, en el extremo, es un narcisista acto 
puro, pensamiento de pensamiento y que da las espaldas al mundo porque, como nos refiere el Libro XII de la Metafísica de Aristóteles, «hay cosas que es mejor no ver que ver»-, la fe heredada del pueblo de Israel se traduce, en cambio, en una confianza personal entre Dios y la humanidad. Si el llamado a misionar es a repetir esa experiencia de amor mutuo, la teología ha de estar a su servicio. La segunda cuestión abordada en estos artículos se refiere a los desafíos que supone a los cristianos la evangelización de la cultura $y$ la inculturación del Evangelio. El evangelizador es un facilitador de la evangelización, pero el agente de la misma es el evangelizado, y la evangelización ha de producirse de modo que pueda ser inteligible para él (ad modum recipientis). Ello supone no solo reconocer la importancia de respetar las culturas, sino de reconocer en ellas lo que ya hay de cristianas, como asimismo reconocer la condición mundana y creatural de la propia Iglesia que evangeliza, y la historicidad de su esfuerzo. Citando a Claude Geffré, la vía de la salvación es el Misterio de Cristo, pero este no se verifica solo ni con mayor claridad en el cristianismo (p. 99). Ello nos pone ante la constatación que la cristiandad es solo un modelo histórico -en consecuencia, relativo y no absoluto- de encarnación de la Iglesia y que luego de más de un milenio y medio de un modelo de Iglesia de cristiandad eurocéntrica, tras el Concilio Vaticano II, estaríamos por primera vez frente a la posibilidad de un cristianismo auténticamente universal, como señalara en su momento Karl Rahner. En ese modelo es posible dialogar con todas las culturas, reconocerlas, discernirlas y promover su reconciliación en cuanto en todas ellas se admite a priori que pueden contener expresiones de la verdad cristiana, que, reiteramos, no es ante todo un credo, sino una experiencia personal amorosa. Por cierto, ello implica una seria pregunta que el padre Costadoat se formula pero que permanece sin responder, dejando al lector en vilo: "¿No se puede afirmar una superioridad cultural bajo ningún respecto? ¿No hay culturas más humanas que otras? ¿Qué sentido tendría evangelizar e inculturar el Evangelio si a fin de cuentas solo Dios sabe qué cultura o qué religión mediatiza a Cristo mejor que otras? El tema puede quedar abierto. Lo que de momento conviene retener, es que el cristianismo cumple su misión cuando promueve la integración cultural. Es esta praxis la que merece ser pensada» (ibíd.).

La segunda parte del libro, varios de cuyos artículos ya han sido aludidos, tiene un marcado énfasis 
cristológico, y en ella descuella el texto «La fe de Jesús, fundamento de la fe en Cristo», al que el propio padre Costadoat concede una importancia primordial en todo el libro. La Iglesia no pudo inventarse una creencia, sino que su fe en Cristo tiene como modelo la fe que el Jesús prepascual tuvo en Dios, a quien llamó Padre. A diferencia de la pistis helénica (asentimiento intelectual a un conjunto de verdades), la emuna judeocristiana es una fidelidad personal a alguien, una respuesta al llamado de Dios, que ha tomado la iniciativa. Esta relación personal y de confianza se produce en la experiencia del Jesús prepascual, quien no solo obedece a un Dios que es alteridad, sino que además responde amorosamente al llamado y al encargo asimismo amoroso del Padre, que supone intimidad. $\mathrm{Y}$ ese llamado es el anuncio del Reino. Porque Jesús no vino a anunciarse a sí mismo, sino al Reino, que es una buena noticia tanto porque promete la liberación de los oprimidos como el perdón de sus pecados a los opresores. La predicación prepascual de Jesús es una anticipación intrahistórica de una salvación escatológica trascendente. Así pues, poner el foco en la fe de Jesús en Dios Padre permite entender mejor el que las autoridades religiosas de la época lo condenaran a morir como un criminal y que su resurrección pudiera ser entendida por la Iglesia primitiva como la rehabilitación de Jesús justo y pobre. Solo entonces la Iglesia primitiva experimentó a Jesucristo como fraternidad, y entendió que el Padre estaba de su lado. Comprender la relación entre la creencia de Jesús prepascual, su predicación del Reino, su condena, su muerte y su resurrección, nos permite escapar a la posibilidad de entender la resurrección como algo descontextualizado en lo que la fe en Cristo es sinónimo de fe en un poder prepotente de Dios, despegado del mundo y de la historia. Por el contrario, al conectar la fe de Jesús, su anuncio del Reino a los pobres, con su resurrección, se recupera como propio de la fe su inserción de la fe en la historia y su compromiso en ella con la liberación de los que sufren injusticia. Se rehabilita por el misterio de la encarnación lo que hay de divino en la creación, y se nos recuerda la mundanidad de la propia Iglesia. El artículo se interroga acerca de la razonabilidad de tener fe religiosa en un hombre, y más aún, en hombre condenado y asesinado. La fe de Jesús en la bondad del llamado de su Padre, que lo compromete con la solidaridad con los injustamente maltratados, y que lo lleva a pade- 
cer por ellos, reviste a Jesús de una autoridad que es autenticidad. En la lógica mundana que privilegia a los vencedores, el grito de Jesús en la cruz representa la razón de los humillados, que en el extremo de su despersonalización en manos de los poderosos reafirman que no son algo sino alguien, que no pueden ser reducidos a cosas. En la resurrección, la Iglesia reconoce en Jesús esa autoridad como autenticidad, porque se hizo uno con los necesitados de justicia y padeció lo que ellos, y por ellos. Y si resucitar a Jesús es rehabilitarlo de su condición de condenado, y darle la razón en su predicación del Reino, resucitar a los pobres y humillados, bajarlos de la crur, es comprometerse para que a ellos se haga también justicia. Jesús tuvo razones para dudar, pero también tuvo razones para creer en su $\mathrm{Pa}$ dre, que finalmente cumplió con él al rehabilitarlo. Con el antecedente de la vida de Jesús como anunciador auténtico del Reino, es posible para la Iglesia tener fe en Cristo. Conservar, pues, la conexión entre la vida del Jesús prepascual y Cristo resucitado permite ensalzar la humanidad de Jesús, y su espiritualidad. Es decir, que Jesús no fue una marioneta de la voluntad de Dios, sino que en él se verificó un proceso espiritual de aceptación libre de la llamada de su Padre, confiado en que este le sería fiel a su promesa. Así pues, a imitación de la fe de Jesús en su Padre, la Iglesia es llamada a tener una fe que supone libertad, autonomía y discernimiento de los fieles en la búsqueda de la voluntad de Dios y en la respuesta positiva a ella. Y en tanto que anuncio del Reino, la Iglesia está llamada a ser lo que el documento de Aparecida llama la casa de los pobres a partir de la cual se intenta cambiar la realidad en aras de mayor justicia y fraternidad.

La tercera parte del libro está dedicada a tres estudios sobre san Alberto Hurtado: su mística social, su vocación intelectual y sus afinidades con la Teología de la Liberación. Estos textos cumplen con la tarea de enriquecer nuestra visión del santo chileno, a quien nos hemos acostumbrado a considerar nada más que como un sacerdote que recogía niños pobres debajo de los puentes. Dicha imagen no hace justicia a la rica complejidad de la figura de Alberto Hurtado, un santo moderno. En su breve vida de apenas cincuenta y un años, reúne, de modo sui generis, una vocación intelectual (heredera de la tradición escolar de la Compañía de Jesús, de diálogo entre la teología y las ciencias humanas, sociales y naturales), y una vocación de apostolado social (que a las exigen- 
cias propias de la caridad agrega aquellas otras propias de la justicia). Pese a no desenvolverse como académico universitario, el padre Hurtado dejó una no despreciable obra escrita y otra obra como la revista Mensaje, para perpetuar una instancia de diálogo entre la fe y la razón, entre cristianos y personas de buena voluntad. Pero una vez más, y a diferencia de ciertas tendencias helenizantes, la eruditio de Hurtado es piadosa y se coloca al servicio de los más pobres, que en este caso son las víctimas masivas de una sociedad injusta. No se trata entonces solo de socorrer a este o aquel pobre en concreto, sino de preguntarse honradamente con los instrumentos que proporciona el conocimiento humano, sobre los orígenes de esa pobreza, y de removerlos en consecuencia, sustituyéndolos por otras instituciones que hagan justicia a la dignidad del pobre. El padre Hurtado no fue un agitador social, sino un estudioso que puso en diálogo su formación teológica con los saberes seculares de su tiempo, y que buscó interlocución no en la cátedra, sino directamente en toda la sociedad. No deja de ser significativo que sus estudios de doctorado lo llevaron a la redacción de una tesis sobre el pensamiento pedagógico de un autor agnóstico, John Dewey. Todo ello se articula a su vez con su mística, que, una vez más a diferencia del modelo helenizante, no se contenta con la sola y callada contemplación del misterio y que en algunos carismas cristianos ha podido conducir a una fuga del mundo, sino que entiende que el seguimiento de Cristo implica hacerse cargo del hecho que Jesús no vino a anunciarse a sí mismo, sino al Reino de Dios Padre, cuya anticipación intrahistórica se traduce en el amor práctico que debemos al prójimo, en la solidaridad con el pobre, en la construcción de la justicia social. Solo entonces se entiende la perfecta coherencia de este ser humano que, al mismo tiempo que podía prestar una colaboración sustancial y competente a la formación de la Facultad de Teología de la Universidad Católica de Chile, pudo fundar la Acción Sindical Chilena a objeto que los mismos trabajadores se prepararan para ser agentes de su propia emancipación social..., para de noche terminar su jornada, ahora sí, rescatando a los niños que dormían bajo los puentes y proporcionarles una sopa caliente, baño y ropa limpia, y una cama decorosa en la que descansar como lo merece la dignidad de la persona.

Decíamos al comenzar que el autor del libro había ordenado en tres grandes secciones sus once ar- 
tículos en razón de su mayor afinidad temática. No obstante, al leer el volumen completo, rápidamente aflora la sensación que el libro como totalidad, más allá de las diferencias formales entre los diversos artículos, se encuentra recorrido por algunas ideas medulares que persistentemente vuelven a aflorar, una y otra vez, en cada una de esas tres grandes secciones, sea que se nos esté contando, por ejemplo, algo sobre algunas cuestiones de la historia de la Teología de la Liberación en América Latina, o de la recepción de las conclusiones de la última Conferencia del Episcopado Latinoamericano en Aparecida, o de la vocación intelectual de san Alberto Hurtado. Son tantas las afinidades que los diversos textos tienen entre sí, que bien podría el lector agruparlos de muchas otras maneras distintas a la que propone el propio autor. Al modo de una arpillera, una vez que se ha podido apreciar lo que muestra por su frontis, no es mala idea mirar en su reverso cómo los diversos hilos se encuentran entrelazados de modos que son invisibles en la figura que ha procurado ofrecernos la arpillerista. La advertencia del P. Costadoat acerca de la posibilidad de leer los textos en un orden aleatorio no solo alivia al lector que, escaso de tiempo, tenga alguna dificultad para emprender a la brevedad la lectura del conjunto total de la compilación. Ese lector puede contar con que la lectura del texto hecha paso a paso será de todos modos fructífera. Además, estimula a todo otro lector a ver este libro ya no como una serie discreta de textos notoriamente separados entre sí, sino más bien como un entramado al que se puede acceder por varios sitios, porque las distintas señales del camino conducen hacia un mismo norte. En este caso, la circularidad que se advierte en el razonamiento del autor no es señal de majadería o de pobreza de ideas que ofrecer y que por eso se machacan tediosamente. Por el contrario, lo que la afinidad entre los textos sugiere es el estar en presencia de un conjunto de ideas fuerza acerca del original quehacer teológico latinoamericano, dotado de una nada despreciable consistencia, que resiste airosamente la prueba de la contrastación a propósito de diversos contextos o problemas, y que puede lidiar de modo fecundo con el desafío que supone articular armoniosamente la novedad del discernimiento de los signos de los tiempos con la asunción de la tradición teológica de la Iglesia desde sus más tempranos comienzos. En último término, esta obra se lee de comienzo a fin, en orden o en desorden, proporcionándonos la experiencia de un punto de 
vista que, formando parte de una incipiente tradición teológica de ya casi medio siglo en la América Latina postconciliar, ha alcanzado la madurez suficiente como para aseverar lo que nos quiere decir al mismo tiempo que puede mirar el camino ya andado y advertir sus flaquezas y fracasos, tanto como sus promesas todavía por cumplir. Como lo sostiene el propio autor al realizar una evaluación del conjunto de la Teología de la Liberación, de sus logros y carencias, «de algún modo (...) ha vuelto al comienzo, pero en modo alguno con las manos vacías» (p. 53).

Cabe felicitar al Centro Teológico Manuel Larraín por este nuevo volumen de su colección Teología de los Tiempos, que de seguro hará una inmensa contribución a su tarea de reunir a teólogos profesionales con teólogos de a pie, a católicos y creyentes junto a otras personas de buena voluntad, en una mejor comprensión de lo que supone ser cristiano en el mundo de hoy. Además, es de agradecer al propio padre
Costadoat por su honrado empeño de argumentar con las cartas sobre la mesa, con las exigencias disciplinares de la teología, pero al mismo tiempo con una prosa que, a la vez que impacta con lo que enseña, nunca deja de ser cordial y literalmente entusiasta. El lector podrá comprobar que en muchas ocasiones la lectura de estos textos desborda una fría recepción puramente intelectual y provoca en él una reflexión en primera persona promovida por un autor que se nos ofrece como interlocutor amistoso, que al igual que la Iglesia en medio de las vicisitudes del mundo moderno, ofrece acompanar nuestro andar lo mismo que pide ser acompañada.

Diego García Monje

Jorge Costadoat, S.J., Trazos de Cristo en América Latina. Ensayos teológicos. Centro Teológico Manuel Larraín, Colección Teología de los Signos de los Tiempos. Ediciones Universidad Alberto Hurtado, Santiago de Chile, 2009, 346 páginas. ISBN 978-956-8421-29-8 